ARTICLE

\title{
Oxoammonium salts are catalysing efficient and selective halogenation of olefins, alkynes and aromatics
}

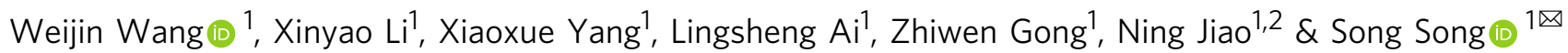

Electrophilic halogenation reactions have been a reliable approach to accessing organohalides. During the past decades, various catalytic systems have been developed for the activation of haleniums. However, there is still a short of effective catalysts, which could cover various halogenation reactions and broad scope of unsaturated compounds. Herein, TEMPO (2,2,6,6-tetramethylpiperidine nitroxide) and its derivatives are disclosed as active catalysts for electrophilic halogenation of olefins, alkynes, and aromatics. These catalysts are stable, readily available, and reactive enough to activate haleniums including $\mathrm{Br}^{+}, \mathrm{I}^{+}$and even $\mathrm{Cl}^{+}$ reagents. This catalytic system is applicable to various halogenations including haloarylation of olefins or dibromination of alkynes, which were rarely realized in previous Lewis base catalysis or Lewis acid catalysis. The high catalytic ability is attributed to a synergistic activation model of electrophilic halogenating reagents, where the carbonyl group and the halogen atom are both activated by present TEMPO catalysis.

\footnotetext{
${ }^{1}$ State Key Laboratory of Natural and Biomimetic Drugs, Peking University, Beijing, China. ${ }^{2}$ State Key Laboratory of Organometallic Chemistry, Chinese

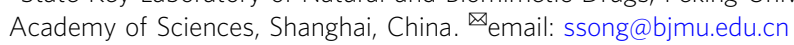


O rganohalides are undoubtedly important chemicals, and have been widely used as the synthetic precursors as well as the target products ${ }^{1-3}$. The carbon-halogen bonds play as a key functional regulator in agrochemicals, materials, natural products, and pharmaceuticals ${ }^{4-6}$. In order to overcome the limitations of electrophilic halogenation with molecular halogen $\left(\mathrm{X}_{2}, \mathrm{X}=\mathrm{Cl}, \mathrm{Br}, \mathrm{I}\right)^{7}$, various electrophilic halogenating reagents have been developed (Fig. 1a $)^{8-10}$. Especially, $\mathrm{Py}_{2} \mathrm{IBF}_{4}{ }^{11-14}$, $\mathrm{Et}_{2} \mathrm{SX} \cdot \mathrm{SbCl}_{5} \mathrm{X}(\mathrm{X}=\mathrm{Br} \text { or } \mathrm{Cl})^{15-18}$, and Palau'chlor ${ }^{19}$ show high efficiency in the construction of $\mathrm{C}-\mathrm{X}$ bonds. In contrast, the very common and readily available $N$-halosuccinimides (NXS, $\mathrm{X}=\mathrm{Cl}$, $\mathrm{Br}, \mathrm{I})$ and dihalo-dimethylhydantoin (DXDMH, $\mathrm{X}=\mathrm{Cl}, \mathrm{Br}, \mathrm{I})$ are practical, stable, and inexpensive, but generally with relative lower reactivity and selectivity (Fig. 1a) ${ }^{20,21}$. For example, Baran et al. ${ }^{19}$ tested the chlorination of anisole with $N$-chlorosuccinimide (NCS), and found that NCS could only chlorinate anisole under the addition of other activators. Therefore, in the past decades, various strategies have been developed to activate NXS or DXDMH for halogenations of unsaturated compounds ${ }^{22}$.

To the best of our knowledge, there are four typical activating strategies to enhance the reactivity of haleniums (Fig. 1b, with NXS as the example). The protonation ${ }^{23-26}$ of carbonyl group in NXS is a widely applied strategy. The Lewis acid ${ }^{27-33}$ could also coordinate with carbonyl group, thus realizing the activation of NXS. The halogen bond reagents could promote the N-X bond cleavage ${ }^{34,35}$, which is beneficial to the electrophilicity of haleniums. Encouraged by Denmark's work ${ }^{36-39}$, Lewis bases, which always bear a donor heteroatom, have been widely employed in activation of haleniums. Up to date, $\mathrm{N}$-centered ${ }^{40-52}, \mathrm{~S}$-centered ${ }^{53-63}$, Se-centered ${ }^{64-70}$, and $P$-centered ${ }^{71,72}$ Lewis bases showed high efficiency in halogenation reactions (Fig. 2a). For example, Borhan ${ }^{44-48}$ and Nicolaou ${ }^{49}$ employed (DHQD) ${ }_{2} \mathrm{PHAL}$ as an efficient catalyst in enantioselective chlorofunctionalization reactions. Yamamoto et al. ${ }^{50}$ reported 2,4,6trimethylaniline catalyzed aromatic halogenation. Besides, morpholine could act as an efficient promoter in haliranium-induced polyene cyclization reported by Gulder et al. ${ }^{51}$. Significantly, the enantioselective halo-polyene cyclization was developed by Ishihara et al. $^{72}$ with phosphoramidites as chiral promoters. Later on, a catalytic asymmetric approach was established by Yamamoto et al. ${ }^{57}$ utilizing a dual-role Lewis base/Brønsted acid catalyst. Denmark et al. ${ }^{64-69}$ disclosed $\mathrm{Se}$-centered catalysts for enantioselective halo-

\section{a Typical electrophilic halogenating reagents}

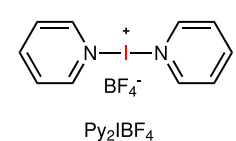

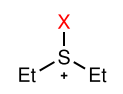

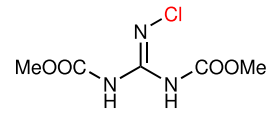

$\mathrm{SbCl}_{5} \mathrm{X}^{-}(\mathrm{X}=\mathrm{Cl}, \mathrm{Br})$

Palau' chlor

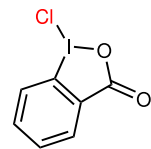

IDSI

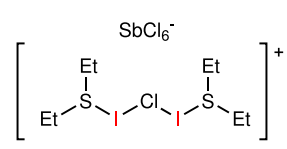

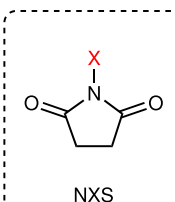

NXS

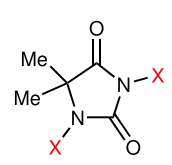

DXDMH b Typical activation models of NXS (X $=\mathrm{Cl}, \mathrm{Br}, \mathrm{I})$

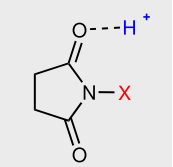

Bronsted acid

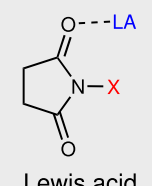

Lewis acid

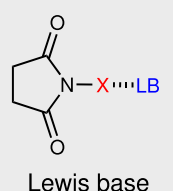

Lewis base

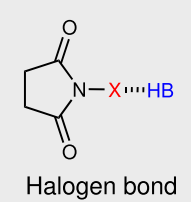

Halogen bond
Fig. 1 Typical electrophilic halogenating reagents and activation models. a Typical electrophilic halogenating reagents. b Typical activation models of NXS. and sulfenofunctionalization reactions. Besides, bifunctional sulfide and selenide catalysis were developed by Zhao et al. for enantioselective halogenation reactions ${ }^{56}$. Yeung et al. found that thioethers ${ }^{58}$, thiocarbamates ${ }^{59-61}$, and selenides ${ }^{70}$ were efficient Lewis base catalysts for enantioselective halofunctionaization reactions. Recently, triptycenyl sulfide showed high catalytic reactivity in electrophilic aromatic halogenation by Nishii and Miura ${ }^{62}$.

Despite the significance of these catalysts, obvious limitations still restricted the wide application of these methods: (1) some challenging halofunctionalization reactions such as intramolecular haloarylation of olefins cannot be achieved with these Lewis base catalysts. (2) Usually, each catalyst can only be compatible with one type of nucleophilic substrates or activate one type of haleniums. There is a short of catalytic method with both broad substrate scope and reaction scope. Compared with above Lewis bases, organic oxides ${ }^{73,74}$ were previously considered inactive for halofunctionalization of unsaturated compounds ${ }^{75}$. Recently, our group reported dimethyl sulfoxide (DMSO) as an efficient catalyst to catalyze the aromatic chlorination reactions ${ }^{76}$. However, the reactive methyl groups ${ }^{77}$ and strong nucleophilicity of DMSO results in the failure to catalyze both bromination or iodination of arenes and halofunctionalization of olefins (Fig. 2b) ${ }^{78-81}$. Thus, the development of effective and diverse catalysts to activate commercially available haleniums, which could cover various halogenation reactions (bromination, iodination, and even

a Previous Lewis base catalysts in halogenation

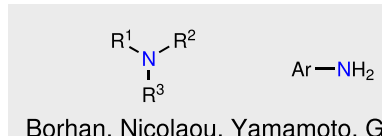

Borhan, Nicolaou, Yamamoto, Gulder

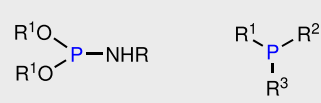

Ishihara, Denmark

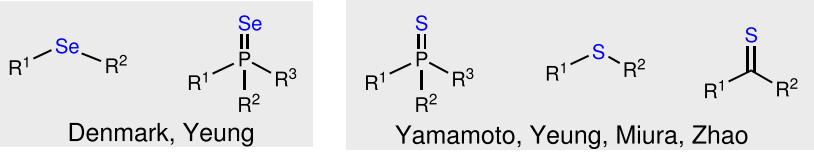

b Limitations of sulfoxides as catalysts in halogenation (Our previous work)

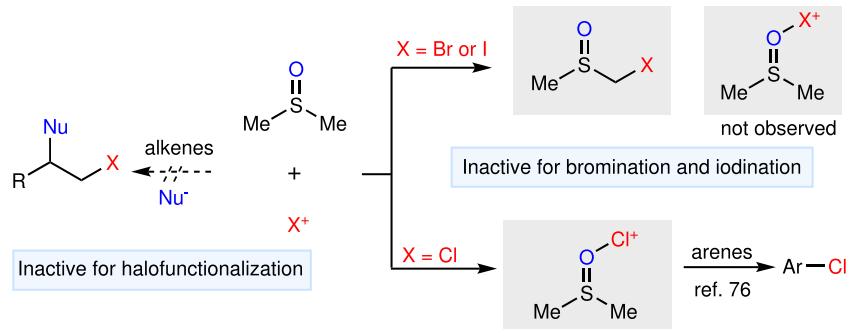

c This work: nitroxides as general catalysts in halogenation

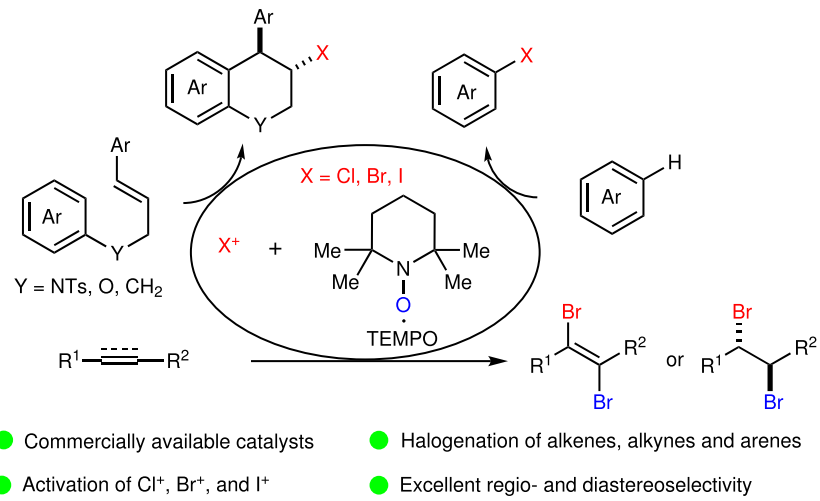

Fig. 2 Overview of previous and current work. a Previous Lewis base catalysts in halogenation. b Limitations of DMSO as catalysts in halogenation. c This work: nitroxides as general catalysts in halogenation. 
a Intramolecular iodo-arylation and bromo-arylation

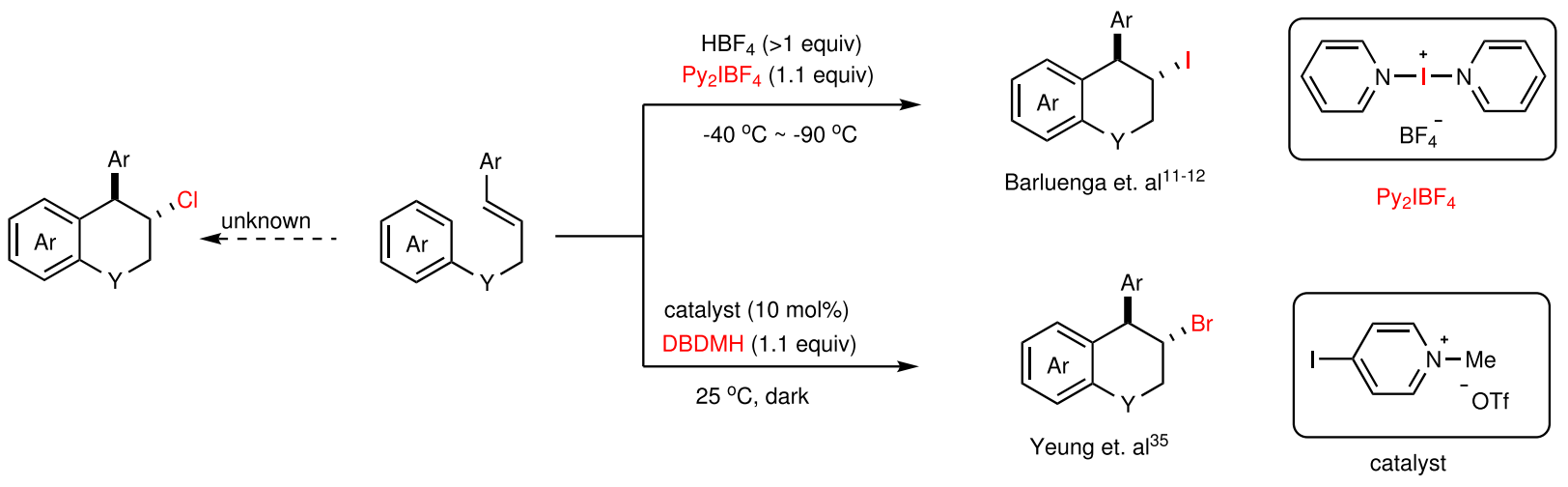

b Intramolecular halo-arylation with $\mathrm{DXDMH}^{\mathrm{a}}$<smiles>Cc1ccc(N([125I])/C=C\c2ccccc2)cc1</smiles>

S1

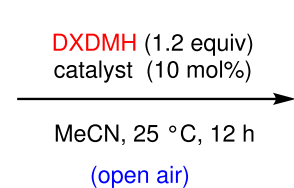

(open air)<smiles>[X]C1CN([Y5])c2ccc(C)cc2[C@H]1c1ccccc1</smiles>

$1, \mathrm{X}=\mathrm{Cl} \quad 2, \mathrm{X}=\mathrm{Br} \quad 3, \mathrm{X}=\mathrm{I}$

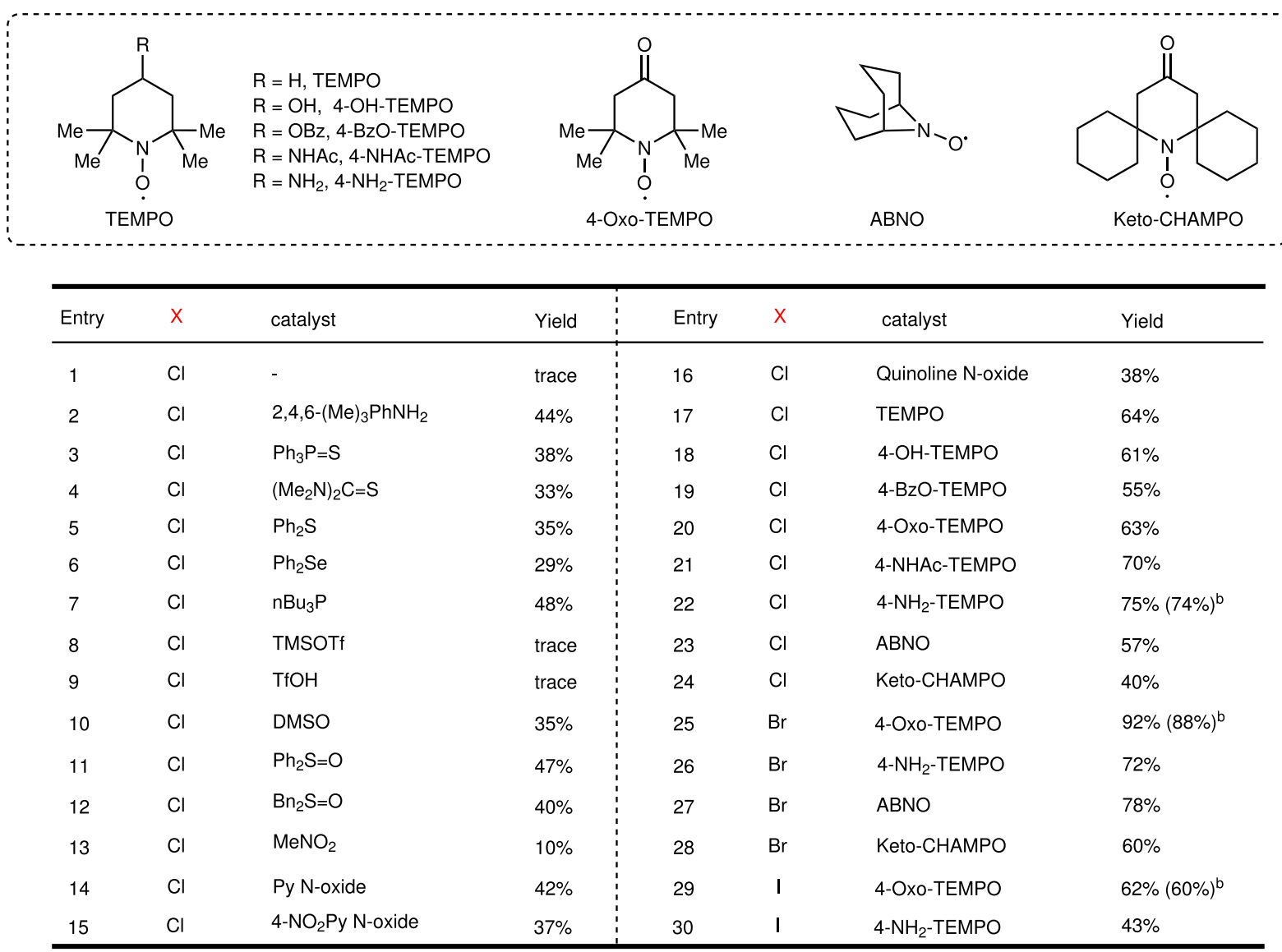

Fig. 3 Optimization of reaction conditions. a Previous reports on intramolecular haloarylation reactions. $\mathbf{b}$ Optimization of reaction conditions. ${ }^{\text {aReactions }}$ were carried out with $\mathbf{S 1}(0.10 \mathrm{mmol})$, catalyst $(0.01 \mathrm{mmol})$ and DXDMH $(0.12 \mathrm{mmol})$ in $\mathrm{MeCN}(1.0 \mathrm{ml})$ for $12 \mathrm{~h}$ at $25^{\circ} \mathrm{C}$. Yields were determined by ${ }^{1} \mathrm{H}$ NMR using 1,1,2,2-tetrachloroethane as the internal standard. blsolated yields of 1-3 for the reaction at $0.20 \mathrm{mmol}$ scale. TsOH p-toluenesulfonic acid, TMSOTf trimethylsilyl trifluoromethylsulfonate. 

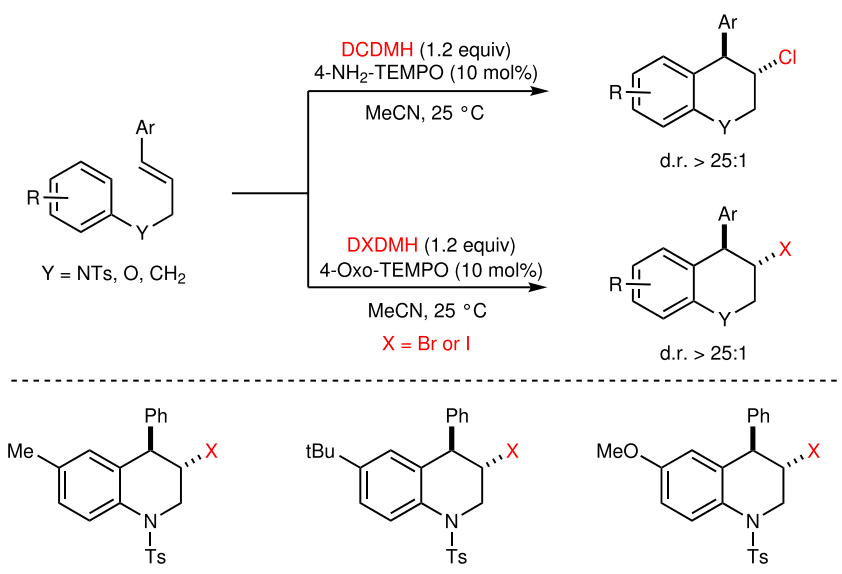

1, $\mathrm{X}=\mathrm{Cl}, 73 \%, 12 \mathrm{~h}$

2, $\mathrm{X}=\mathrm{Br}, 88 \%, 8 \mathrm{~h}$

$3, X=I, 62 \%, 18 \mathrm{~h}$<smiles>[X]C1CN([Y5])c2ccccc2C1c1ccccc1</smiles><smiles>[X]C1CN([As])c2ccc(F)cc2C1c1ccccc1</smiles>

13, $\mathrm{X}=\mathrm{Cl}, 36 \%,{ }^{\mathrm{b}} 24 \mathrm{~h}$ $14, \mathrm{X}=\mathrm{Br}, 59 \%,{ }^{\text {b }} 24 \mathrm{~h}$ $11, X=B r, 82 \%, 4 h$ $12, X=1,52 \%, 24 \mathrm{~h}$<smiles>[X]C1CN([Y5])c2cc3c(cc2C1c1ccccc1)OCO3</smiles>

17, $\mathrm{X}=\mathrm{Cl}, 65 \%,{ }^{\mathrm{c}} 1 \mathrm{~h}$ $18, \mathrm{X}=\mathrm{Br}, 88 \%, 4 \mathrm{~h}$ $19, X=1,90 \%, 12 h$

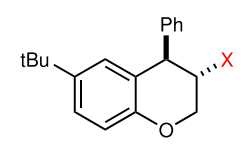

$24, \mathrm{X}=\mathrm{Br}, 79 \%, 10$ $25, X=I, 73 \%, 24 h$<smiles>[X]C1CN([As])c2ccccc2C1Br</smiles>

$\mathrm{Ar}=4-\mathrm{ClC}_{6} \mathrm{H}_{4}$ 20, $\mathrm{X}=\mathrm{Cl}, 52 \%, 8 \mathrm{~h}$ $21, \mathrm{X}=\mathrm{Br}, 70 \%,{ }^{\mathrm{c}} 4 \mathrm{~h}$

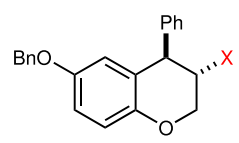

26, $\mathrm{X}=\mathrm{Br}, 76 \%, 8 \mathrm{~h}$ $27, \mathrm{X}=\mathrm{I}, 78 \%, 12 \mathrm{~h}$
7, $\mathrm{X}=\mathrm{Cl}, 84 \%, 4 \mathrm{~h}$ $8, X=B r, 95 \%, 2 h$
$9, X=1,72 \%, 12 h$

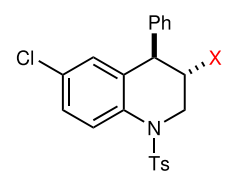

$15, \mathrm{X}=\mathrm{Cl}, 48 \%,{ }^{\mathrm{b}} 24 \mathrm{~h}$ $16, X=B r, 50 \%,{ }^{b} 12 h$<smiles>[X]C1COc2ccc(OC)cc2C1c1ccccc1</smiles>

22, $\mathrm{X}=\mathrm{Br}, 96 \%, 1 \mathrm{~h}$ 23, $X=1,80 \%, 4 h$

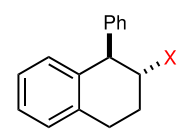

28, $X=B r, 92 \%, 12 h$ $29, \mathrm{X}=\mathrm{l}, 63 \%, 2 \mathrm{~h}$

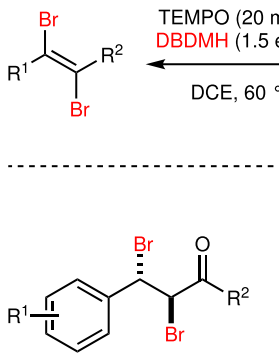<smiles>O=C1CCC[C@@H](Br)[C@H]1Br</smiles><smiles>COC(=O)[C@]1(Br)CCC[C@@H]1Br</smiles><smiles>CC(Br)[C@H](Br)c1ccccc1</smiles><smiles>BrCC(Br)[C@H](Br)c1ccccc1</smiles>

$37,65 \%, 20 \mathrm{~h}$ $38, n=1,85 \%, 20 h$
$39, n=2,95 \%, 20 h$

$40,51 \%,^{c} 1 \mathrm{~h}$

$41,76 \%,{ }^{\mathrm{c}} 20 \mathrm{~h}$

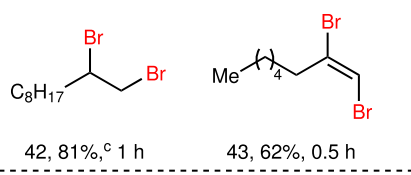

aReactions were carried out with alkene or alkyne $(0.50 \mathrm{mmol})$, TEMPO

Fig. 4 TEMPO-catalyzed haloarylationa. aReactions were carried out with substrate $(0.20 \mathrm{mmol})$, catalyst $(0.02 \mathrm{mmol}), \mathrm{DXDMH}(0.24 \mathrm{mmol}), \mathrm{MeCN}$ $(2.0 \mathrm{~mL})$ at $25^{\circ} \mathrm{C}$ unless specified. Isolated yield. beactions were carried out with substrate $(0.20 \mathrm{mmol})$, catalyst $(0.04 \mathrm{mmol}), \mathrm{DXDMH}(0.30 \mathrm{mmol})$, $\mathrm{MeNO}_{2}(3.0 \mathrm{ml})$ at $60^{\circ} \mathrm{C}$ under air. ${ }^{\mathrm{C}} 5 \mathrm{~mol} \%$ of catalyst was used.

chlorination) and broad scope of unsaturated compounds (olefins, arenes, and alkynes) to overcome the existing limitations in the halogenation field, is very urgent. Our inspiration came from the formation enthalpies of the iodine complexes with Lewis bases $^{82}$. The absolute values of enthalpies paralleled with their catalytic activities in the halofunctionalization reactions ${ }^{75}$. Some nitroxides showed quite high enthalpies, therefore, we speculated that nitroxides could activate electrophilic halogenating reagents.

In this work, TEMPO $^{+}$and its derivatives, which could be generated in situ from commercially available TEMPO ${ }^{83-86}$ and electrophilic halogenating reagents, were developed as diverse and efficient catalysts in various halogenation reactions. Besides bromonium and iodonium, the chloronium was also strongly activated by catalytic amount of $\mathrm{TEMPO}^{+}$. The strong activating ability and low nucleophilicity of TEMPO make the tolerance of olefins, alkynes, and arenes possible, thus overcoming the inherent limitations of previous sulfoxide catalysis ${ }^{76}$. Based on the high reactivity,

$44, \mathrm{R}=\mathrm{H}, 58 \%, 3 \mathrm{~h}$ $45, \mathrm{R}=\mathrm{Me}, 73 \%, 3 \mathrm{~h}$ $46, \mathrm{R}=\mathrm{nBu}, 70 \%, 3 \mathrm{~h}$ $47, \mathrm{R}=\mathrm{Ph}, 73 \%, 3 \mathrm{~h}$

Fig. 5 TEMPO-catalyzed dibromination of alkenes and alkynes ${ }^{a}$. $(0.10 \mathrm{mmol}), \mathrm{DBDMH}(0.75 \mathrm{mmol}), \mathrm{DCE}(2.0 \mathrm{ml})$ at $60^{\circ} \mathrm{C}$ under air. Isolated yield. bThe catalyst was added twice in total $20 \mathrm{~mol} \%$. ${ }^{\mathrm{C}}$ Performed at $25^{\circ} \mathrm{C}$.

the intramolecular haloarylation of olefins, dibromination of olefins, and alkynes, as well as aromatic halogenation of arenes were realized with good selectivity and efficiency (Fig. 2c).

\section{Results and discussion}

TEMPO-catalyzed intramolecular haloarylation of olefins. The intramolecular haloarylation of olefins provides a convenient protocol to valuable synthetic intermediates ${ }^{87,88}$. The iodo- and bromoarylation of olefins have been well realized by Barluenga ${ }^{11,12}$ and Yeung ${ }^{35}$. However, the chloroarylation was more challenging and rarely realized based on two reasons: (1) the unstability of chloriranium ion makes it more likely to form a free carbocation, resulting in low stereoselectivity or decomposition; (2) the chlorenium ion is more reactive so that it tends to react with nucleophiles before forming a chloriranium ion (Fig. 3a). Therefore, developing a versatile synthetic system for all chloro-, bromo- and iodo-arylation under mild reaction conditions is still in great need. Thus, the chloroarylation of S1 was initially investigated in $\mathrm{MeCN}$ at $25^{\circ} \mathrm{C}$ with $\mathrm{DCDMH}$ as the chloro-source (Fig. 3b). In the absence of catalyst, DCDMH was not active enough to promote the cyclization, and only trace amount of 1 was detected (Entry 1). The classical Lewis base catalysts, including 2,4,6-trimethylaniline, $\mathrm{Ph}_{3} \mathrm{P}=\mathrm{S}$, thiourea, $\mathrm{Ph}_{2} \mathrm{~S}, \mathrm{Ph}_{2} \mathrm{Se}, n \mathrm{Bu}_{3} \mathrm{P}$ showed low reactivity (Entries 2-7). Lewis acid TMSOTf or Brønsted acid TsOH could not catalyze the transformation from $\mathbf{S 1}$ to $\mathbf{1}$ (Entries 8-9). The sulfoxides including DMSO, $\mathrm{Ph}_{2} \mathrm{~S}=\mathrm{O}$, and $\mathrm{Bn}_{2} \mathrm{~S}=\mathrm{O}$ could not catalyze this reaction efficiently (Entries 10-12). Then, a series of reagents bearing $\mathrm{N}-\mathrm{O}$ bond(s) were tested (Entries 13-16). Nitromethane, which promoted the fluorination efficiently ${ }^{89}$, failed to catalyze this reaction (Entry 13). The $N$-oxides of pyridine, 4 -nitropyridine, and quinoline showed similar catalytic activity with sulfoxides (Entries 14-16). To our delight, the yield of 1 increased to $64 \%$ with $10 \mathrm{~mol} \%$ of TEMPO as the catalyst (Entry 17). 4-OH, 4$\mathrm{BzO}$, or 4-Oxo substituted TEMPO gave similar yields with TEMPO (Entries 18-20), and 4- $\mathrm{NH}_{2}$-TEMPO gave the highest $75 \%$ yield (Entries $21-22$ ). TEMPO analogs bearing different $\alpha$ - 
substituents ${ }^{90}$ still promoted the chloroarylation, although with lower yields (Entries 23-24). The TEMPO catalysis was also successfully applied in the bromo- and iodo-arylation of S1, and 4 -Oxo-TEMPO showed highest catalytic reactivity ( 88 and $62 \%$ yields, Entries 25-30).

With $10 \mathrm{~mol} \%$ of TEMPO derivatives as the catalysts, the substrate scope of this intramolecular haloarylation was examined (Fig. 4). The present catalytic system exhibited high diastereoseletivity and regioselectivity, and no aromatic halogenated products were detected. Generally, the yields of bromoarylation were higher than that of chloro- and iodo-arylation. The haloarylation of $\mathrm{N}$-cinnamyl sulfonamides proceeded smoothly to give the desired tetrahydroquinolines 1-21 in good efficiencies. Electron-donating group substituted substrates are favorable for this transformation and could be smoothly converted into cyclic products in excellent yields. Electron-withdrawing groups such as fluorine and chlorine atoms could also be tolerated in the reaction system under specified conditions, although with moderate yields due to incomplete conversion of the substrates. The bromo- and iodo-arylation of $\mathrm{O}$-cinnamyl ethers underwent smoothly to afford chromane building blocks 22-27 in high yields. Exposure of $(E)$-but-1-ene-1,4-diyldibenzene under standard conditions delivered tetrahydronaphthalene $\mathbf{2 8 - 2 9}$ in good yields.

TEMPO-catalyzed dibromination of alkenes and alkynes. Meanwhile, we noticed that $\mathrm{X}^{-}$was generated in situ when TEMPO was oxidized by DXDMH. If the $\mathrm{Br}^{-}$rather than arenes acted as the nucleophile (the excess bromide anions might come from in situ hydrolysis and disproportionation, see Supplementary Figs. 10-12), the dibromination of olefins would be realized. In this case, TEMPO not only functioned as an activator, but also a redox catalyst to generate $\mathrm{X}^{-}$. With this hypothesis, the dibromination of $\alpha, \beta$-unsaturated carbonyl compounds ${ }^{91-93}$, which

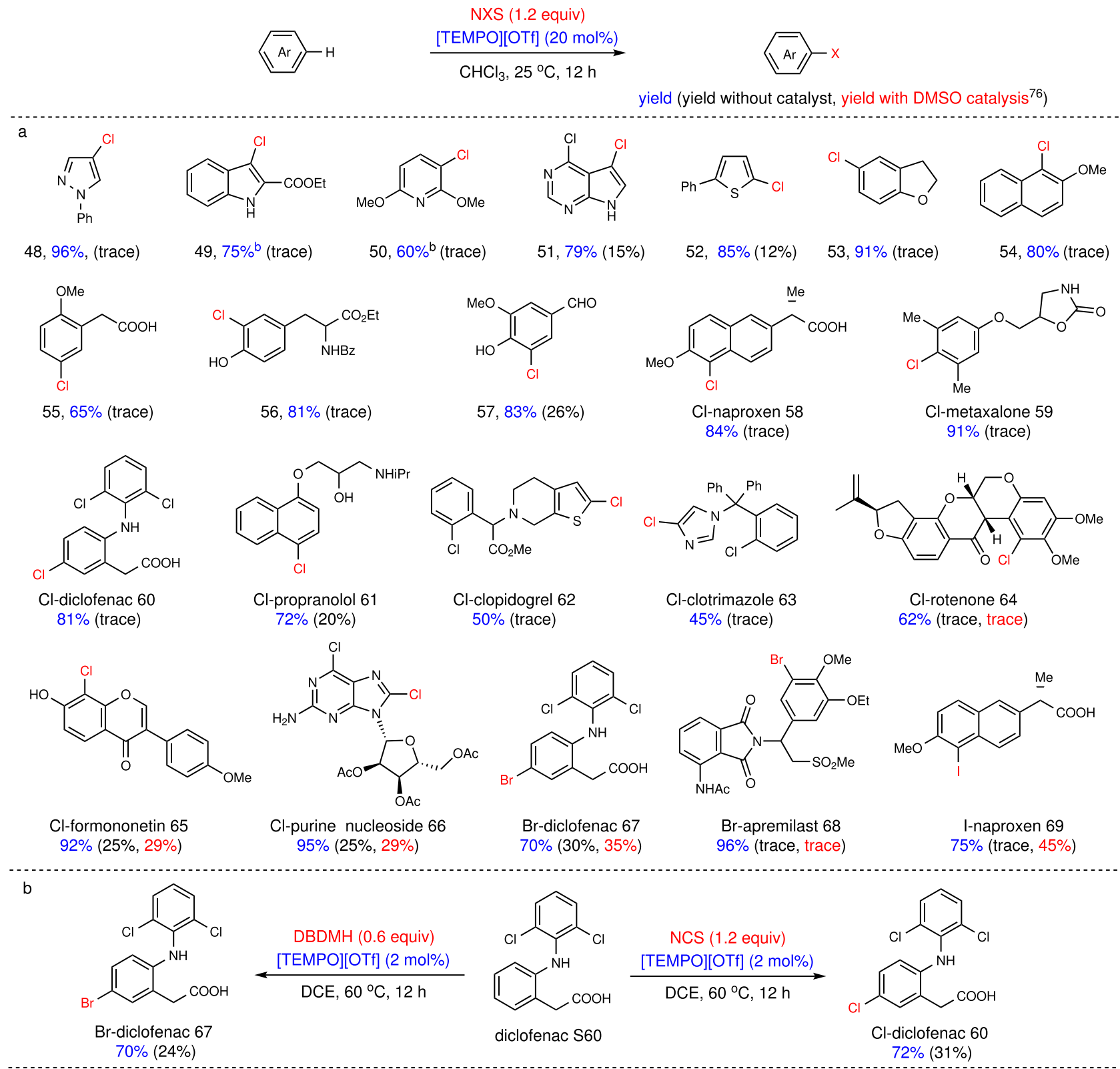

Fig. 6 TEMPO-catalyzed halogenation of (hetero)arenes ${ }^{a}$. aReactions were carried out with arene $(0.50$ mmol), NXS (0.60-0.75 mmol), and [TEMPO] [OTf] $(0.10 \mathrm{mmol})$ in $\mathrm{CHCl}_{3}(2.0 \mathrm{ml})$ at $25^{\circ} \mathrm{C}$ under air for $12 \mathrm{~h}$. Isolated yield. The black number in parentheses was the yield without catalyst, and the red number in parentheses was the yield with $20 \mathrm{~mol} \%$ of DMSO as the catalyst. berformed with NCS $(1.0 \mathrm{mmol})$. 
always afforded products in low diastereoselectivity with molecular $\mathrm{Br}_{2}$, was tested with TEMPO as the catalyst (Fig. 5). Chalcone and its derivatives were dibrominated with high yields (30-31), and it is noteworthy that the diastereoselectivity of this transformation is very high $(>25: 1)$. The dibromination of cinnamates also underwent smoothly to deliver 33-36 with good efficiency. Cyclic olefins were dibrominated to afford antiproducts 37-39 bearing tertiary and quaternary $\mathrm{C}-\mathrm{Br}$ bond in good yields. Besides electron-deficient olefins, the dibromination of styrene derivatives and aliphatic olefins also worked very well (40-42) with excellent diastereoselectivity.

Inspired by the above success, the dibromination of alkynes was tested with present TEMPO/DBDMH system to realize the efficient synthesis of $(E)$-dibromoolefins. Aliphatic or aromatic alkynes, internal or terminal alkynes were all dibrominated to afford (E)-dibromoolefins in good yields (43-47).

TEMPO-catalyzed halogenation of (hetero)arenes. Electrophilic aromatic halogenation is perhaps the most direct approach to afford aryl halides, which is very important in pharmaceutical sciences ${ }^{6}$. Compared with bromination and iodination, the aromatic chlorination of arenes is relatively more challenging. Interestingly, mechanistic studies revealed that TEMPO was in situ oxidized by haleniums to $\mathrm{TEMPO}^{+}$, which was the real catalyst to promote haloarylation reactions (see below). Encouraged by the above results, the chlorination of many (hetero)arenes, which could not be chlorinated effectively without a catalyst (yields $<26 \%$, see Supplementary Information), was investigated by [TEMPO][OTf] catalysis with NCS (Fig. 6a). Various aromatics including benzene, indole, pyrazole, pyridine, and thiophene were chlorinated in high yields and excellent regioselectivity at room temperature (48-57). The ester, amide, hydroxyl, carboxylic acid, aldehyde groups were all tolerated in the present catalysis.

The mild reaction conditions and excellent functional group tolerance enabled this protocol to be applied in the late-stage halogenation of drugs and natural products (Fig. 6a). Many drugs containing various functional groups which restrict their chlorination, underwent the chlorination smoothly under the present [TEMPO][OTf] catalysis to afford the corresponding products in good yields and selectivities (58-69). The chlorination of propranolol, diclofenac, or metaxalone with NCS only afforded trace amount of product, maybe because the amines or hydroxyl groups restricted the chlorination. Gratifyingly, the above drugs were chlorinated in good yields and selectivities in the presence of catalytic [TEMPO][OTf] (59-61). Clopidogrel bearing benzene and thiophene cycles was selectively chlorinated at the thiophene position (62). The $N$-heterocycle of clotrimazole was chlorinated under the standard conditions (63). TEMPO ${ }^{+}$ catalysis showed better functional group tolerance than that of DMSO. The chlorination of rotenone, formononetin, and purine analog did not work in previous DMSO catalysis ${ }^{76}$, but were significantly promoted by $\mathrm{TEMPO}^{+}$with the survival of olefin, ketone, and sugar motif (64-66). The TEMPO ${ }^{+}$catalysis was also successfully applied in the late-stage bromination and iodination of bioactive molecules (67-69), which showed very low efficiency in previous DMSO catalysis ${ }^{76}$. It is noteworthy that the present TEMPO $^{+}$catalysis showed higher efficiency than that of other catalysts for the chlorination of diclofenac (see Supplementary Table 5) and the catalyst loading can be reduced to $2 \mathrm{~mol} \%$ under $60{ }^{\circ} \mathrm{C}$ (Fig. 6b).

Mechanistic studies. To investigate the mechanism of TEMPOcatalyzed halogenation, several mechanistic experiments were conducted. The haloarylation underwent smoothly in the presence of 2.0 equiv of BHT (see Supplementary Information), which indicated radical process may be not involved in the system. In order to illustrate the relative activity of TEMPO and [TEMPO][OTf], we further performed the bromoarylation reaction and aromatic halogenation reaction with various loadings of the catalyst. The bromoarylation of $\mathbf{S 1}$ was promoted moderately by $10 \mathrm{~mol} \%$ of TEMPO to afford $68 \%$ yield, and the yield could be significantly increased by only $2 \mathrm{~mol} \%$ of [TEMPO][OTf] catalyst (Fig. 7, Eq. (1)). The same rule was exhibited in the aromatic chlorination of diclofenac S60 (Fig. 7, Eq. (2)). These experiments indicate that TEMPO $^{+}$is the real catalyst to activate haleniums and we attributed the lower yields obtained by TEMPO catalysis to the different counterions formed in the system (Supplementary Tables 11 and 12). Besides, the reaction of TEMPO and DBDMH in MeCN was monitored (Fig. 7, Eq. (3)), and the formation of $\mathrm{TEMPO}^{+}$was confirmed by HRMS-ESI analysis, which is identical with previous reports ${ }^{94,95}$. When NCS and [TEMPO][OTf] was mixed in MeCN, the signal of active intermediate [TEMPO-NCS] ${ }^{+}$was detected by HRMS (Fig. 7, Eq. (4)).

To further illustrate the roles of $\mathrm{TEMPO}^{+}, \mathrm{NMR}$ titration studies were conducted. The ${ }^{13} \mathrm{C}-\mathrm{NMR}$ chemical shift of $\mathrm{C}-2$ in DBDMH shifted to a lower field with the increasing amount of TEMPO $^{+}$(Fig. 8a), indicating that the electron density of $C-2$ was decreased in the presence of $\mathrm{TEMPO}^{+}$. This result was similar with that of typical Lewis acid $\operatorname{In}(\mathrm{OTf})_{3}$ (see Supplementary Fig. 2), suggesting that the positive nitrogen in $\mathrm{TEMPO}^{+}$ functioned as a potential Lewis acid. Furthermore, inspired by previous reports on phosphoxides as a common probe to measure

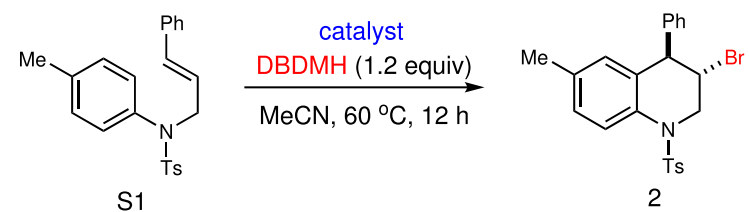

10 mol\% TEMPO: $68 \%$

$2 \mathrm{~mol} \%$ [TEMPO][OTf]: $88 \%$
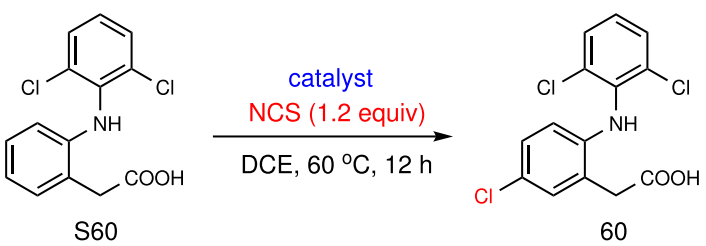

60

5 mol\% TEMPO: $32 \%$ 2 mol\% [TEMPO][OTf]: $72 \%$
(I)

$\mathrm{DBDMH}$
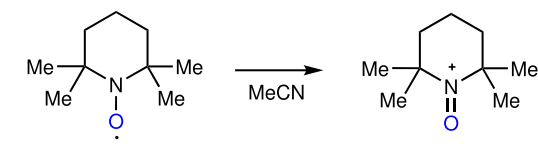

$\mathrm{TEMPO}^{+}$ HRMS: 156.1387
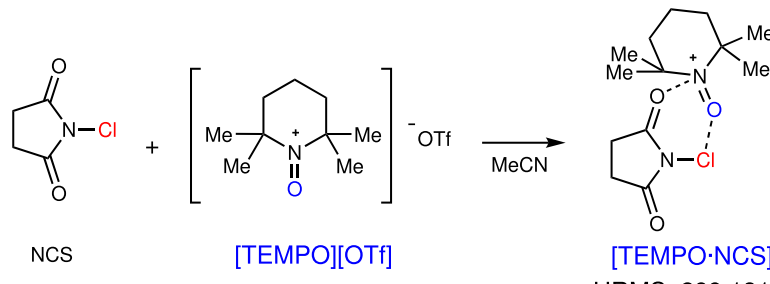

[TEMPO-NCS] $]^{+}$ HRMS: 289.1317
Fig. 7 Control experiments. The results in Eqs. (1) and (2) indicate that $\mathrm{TEMPO}^{+}$is the real catalyst to activate haleniums. The formation of $\mathrm{TEMPO}^{+}$and [TEMPO.NCS ${ }^{+}$was detected by HRMS as shown in Eqs. (3) and (4). 
Lewis acidity ${ }^{96-98}$, the result of ${ }^{31} \mathrm{P}-\mathrm{NMR}$ chemical shift of $\mathrm{Ph}_{3} \mathrm{P}$ $=\mathrm{O}$ shifted to a lower field with increasing amount of $\mathrm{TEMPO}^{+}$ confirmed the Lewis acidic property of TEMPO $^{+}$(Fig. 8b). Besides, the initial reaction rate was accelerated with the increment of [TEMPO][OTf] or DBDMH, and therefore firstorder dependences of [TEMPO][OTf] and DBDMH were both established (Fig. 8c, d), which suggested that one [TEMPO][OTf] molecule was involved in the activation of DBDMH.

To explain the activation of the $\mathrm{TEMPO}^{+}$-catalyzed halogenation, DFT calculations ${ }^{99}$ were carried out. The halogenating reagents interacts with $\mathrm{TEMPO}^{+}$toward two directions as the methyl groups stand in axial or equatorial bond, in which the equatorial bond side has more space for the interaction with lower stabilization energy than the axial bond one (Fig. 8e). The calculation result indicates that NXS or DXDMH forms a complex with $\mathrm{TEMPO}^{+}$toward the equatorial bond direction and the stabilization energy is $7.6-9.5 \mathrm{kcal} / \mathrm{mol}$. The $\mathrm{N}$-atom of $\mathrm{TEMPO}^{+}$interacts with $\mathrm{O}$ atom of the halogenating reagents (N-O distance: $2.75-2.79 \AA$ ), while O-atom of TEMPO ${ }^{+}$interacts weekly with $\mathrm{X}$ atom of the halogenating reagents $(\mathrm{O}-\mathrm{X}$ distance: 3.15-3.36 ̊). The latter interaction also causes slight stabilization. The atomic charges were calculated using Mulliken population

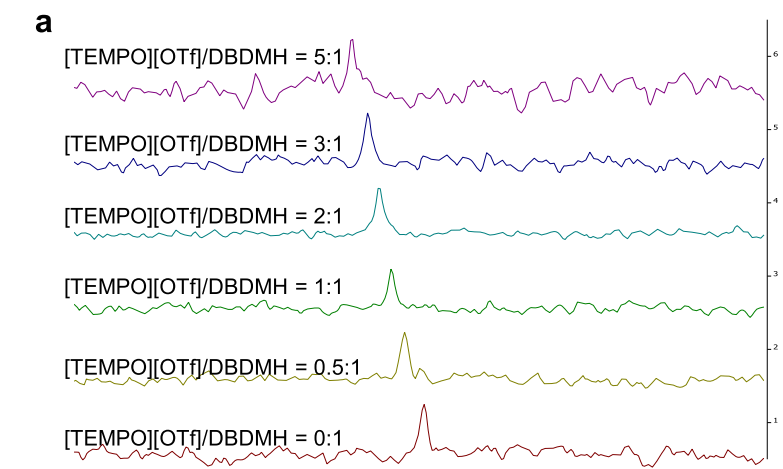

C

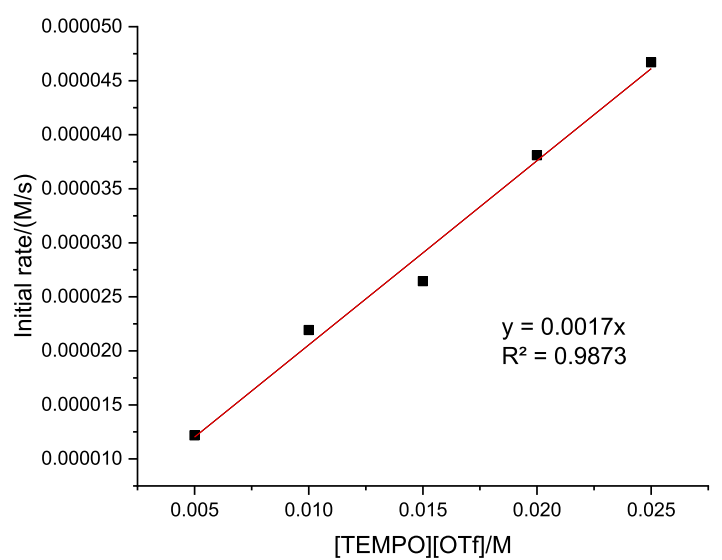

b

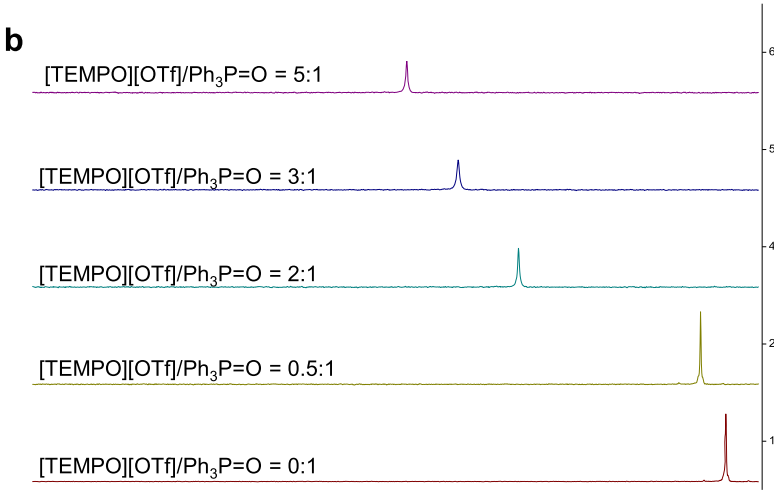

d
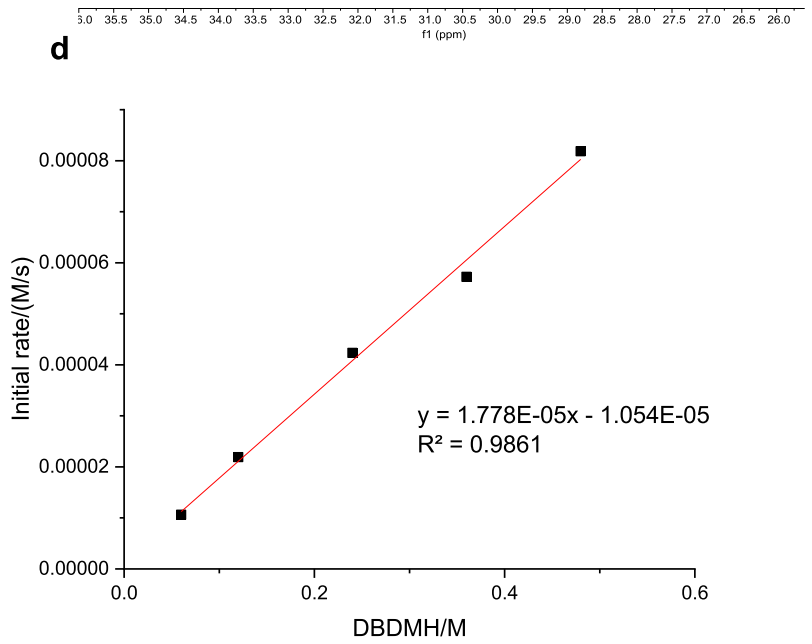

e Mulliken charge of $\mathrm{Cl}:+0.233$ in NCS and +0.345 in DCDMH, Br: +0.152 in NBS and +0.169 in DBDMH

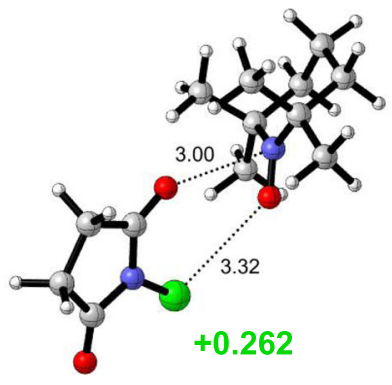

NCS-TEMPO+

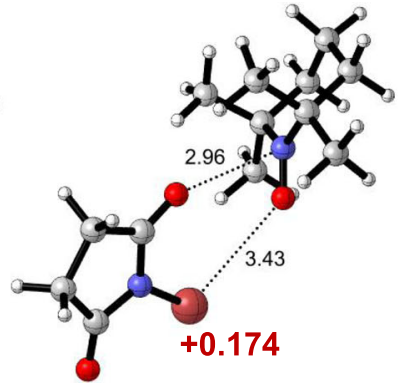

NBS-TEMPO+

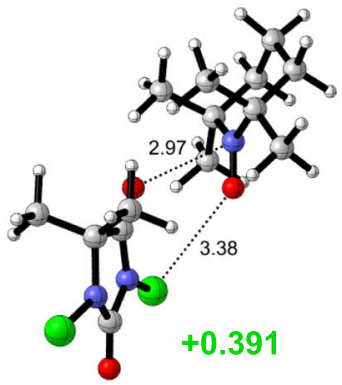

DCDMH -TEMPO+

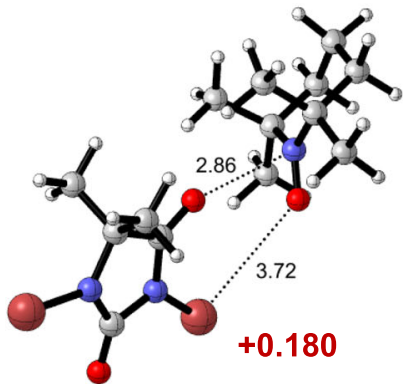

DBDMH -TEMPO+

$$
\Delta E_{\mathrm{CHCl3}}=-5.9
$$

$$
\Delta E_{\mathrm{MeCN}}=-5.2
$$

$-5.8$

Fig. 8 Mechanistic studies. a ${ }^{13} \mathrm{C}-\mathrm{NMR}$ titration experiment between $\mathrm{DBDMH}$ and [TEMPO][OTf]. ${ }^{31} \mathrm{P}-\mathrm{NMR}$ titration experiment between $\mathrm{Ph}_{3} \mathrm{P}=\mathrm{O}$ and [TEMPO][OTf]. c Kinetic study of [TEMPO][OTf]. d Kinetic study of DBDMH. e Plausible intermediate from halogenating reagents and TEMPO ${ }^{+} . \Delta E$ is energy change associated with halogenating reagent $\mathrm{TEMPO}^{+}$complex formation $(\Delta E$ unit: $\mathrm{kcal} / \mathrm{mol}$ ). 


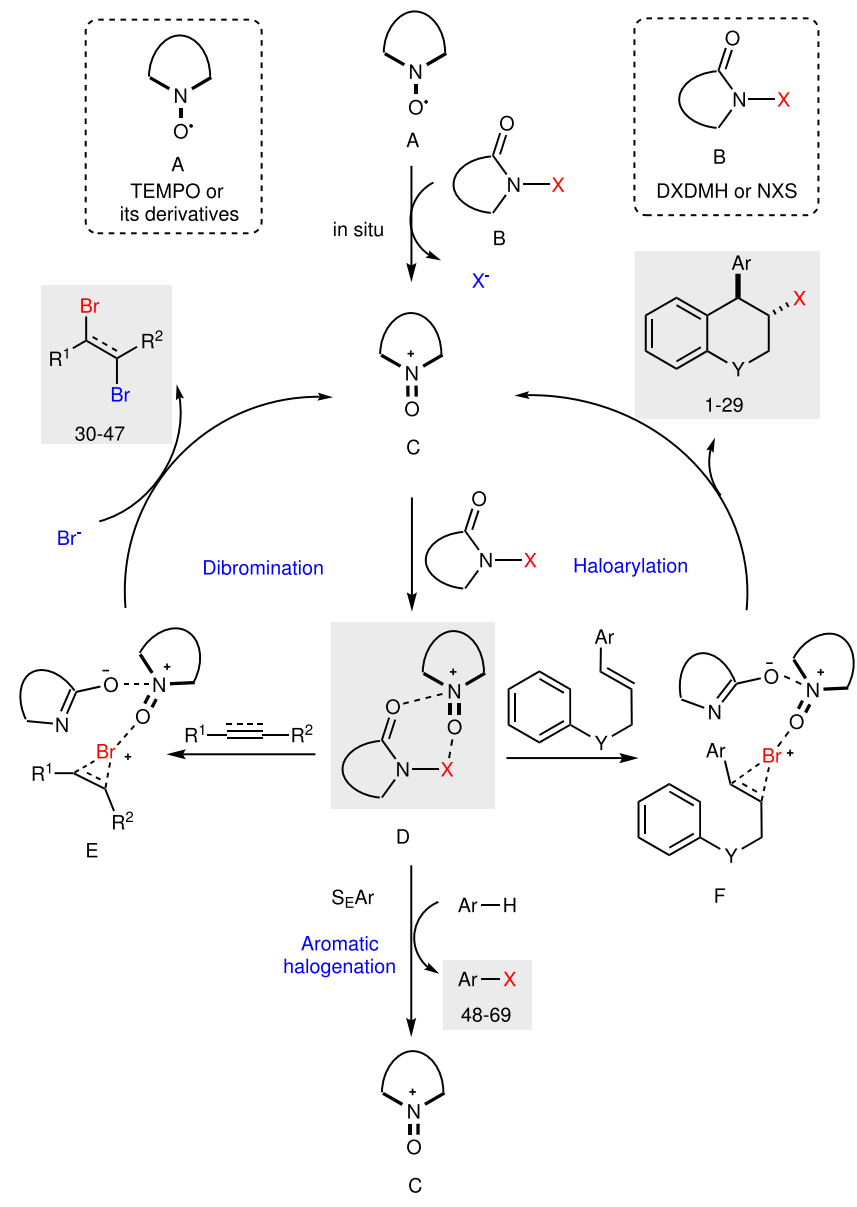

Fig. 9 Proposed mechanism. The electropositive ammonium of $\mathrm{N}=\mathrm{O}$ bond could interact with the carbonyl group of halenium reagents to decrease their electron density, and enhance their electrophilicity. Meantime, the oxygen atom on $\mathrm{TEMPO}^{+}$could function like a Lewis base to form a polarized complex with halogenating reagents, which synergistically activates the haleniums

analysis. The calculated atomic charges show that the positive charge on the $\mathrm{Cl}$ atom of the halogenating reagent $\mathrm{TEMPO}^{+}$ complex is larger than that of isolated halogenating reagents, while the positive charge on the $\mathrm{Br}$ atom changes slightly. These results suggest that $\mathrm{TEMPO}^{+}$could form a synergistic activation model of electrophilic halogenating reagents, where the carbonyl group and the halogen atom were both activated by TEMPO ${ }^{+}$ catalysis. $\mathrm{TEMPO}^{+}$has short $\mathrm{N}-\mathrm{O}$ distance with halogenating reagent, positive charge on the $\mathrm{Cl}$ atom, and low stabilization energy, which performs as a robust catalyst.

Based on the above results and previous reports ${ }^{76,86}$, a plausible mechanism of present TEMPO catalysis is proposed (Fig. 9). The reaction is initiated with in situ oxidation of TEMPO A to $\mathrm{TEMPO}^{+} \mathbf{C}$ by electrophilic halogenating reagents $\mathbf{B}$, with the generation of $\mathrm{X}^{-}$. Then $\mathbf{C}$ interacts with halenium $\mathbf{B}$ to afford activated halogenating species $\mathbf{D}$, which was confirmed by HRMS analysis. Two important features of $\mathrm{TEMPO}^{+}$contribute to the enhanced reactivity of intermediate $\mathbf{D}$. First, the electropositive ammonium of $\mathrm{N}=\mathrm{O}$ bond could interact with the carbonyl group of halenium reagents to decrease their electron density, and enhance their electrophilicity. Meantime, we speculated the oxygen atom on $\mathrm{TEMPO}^{+}$could function like a Lewis base to form a polarized complex with halogenating reagents, which synergistically activates the haleniums. Therefore, the highly reactive intermediate $\mathbf{D}$ could interact with alkenes or alkynes for the subsequent formation of halenium intermediate $\mathbf{E}$ or $\mathbf{F}$, which is easily attacked by arene or bromine ion to deliver the corresponding products, with the regeneration of $\mathrm{TEMPO}^{+} \mathbf{C}$. The aromatic halogenation would deliver aryl halides via $\mathrm{S}_{\mathrm{E}} \mathrm{Ar}$ process when intermediate $\mathbf{D}$ is treated with arenes.

In summary, readily available TEMPO and its derivatives have been developed as efficient catalysts to catalyze halogenation reactions. The high catalytic activity and good functional group tolerance of $\mathrm{TEMPO}^{+}$made it compatible with the halogenation of arenes, olefins, and alkynes, including the haloarylation of olefins and dibromination of alkynes, which were rarely achieved by other methods. This chemistry would provide reliable catalysis in the synthesis of organohalides and promote the design and development of new catalysis in organic synthesis.

\section{Methods}

General procedure for TEMPO-catalyzed haloarylation. Substrate S1-S12 $(0.20$ $\mathrm{mmol})$, DXDMH $(0.24 \mathrm{mmol})$, the catalyst $(0.02 \mathrm{mmol})$, and $\mathrm{MeCN}(2.0 \mathrm{ml})$ were added to a reaction tube with a magnetic bar. The mixture was stirred at $25^{\circ} \mathrm{C}$ for the specified reaction time. Upon completion of the reaction (monitored by TLC), the reaction mixture was quenched with saturated $\mathrm{Na}_{2} \mathrm{SO}_{3}$ aqueous solution $(2 \mathrm{ml})$. The aqueous phase was diluted with water $(3 \mathrm{~mL})$ and extracted with EtOAc $(5$ $\mathrm{ml} \times 3$ ). The combined organic extracts were dried over anhydrous $\mathrm{Na}_{2} \mathrm{SO}_{4}$, filtered, and concentrated under reduced pressure. The residue was purified over silica gel chromatography to afford 1-29.

General procedure for TEMPO-catalyzed debromination of alkenes and alkynes. Substrate S30-S47 (0.50 mmol), DBDMH ( $0.75 \mathrm{mmol})$, TEMPO $(0.10$ $\mathrm{mmol})$, and DCE $(2.0 \mathrm{ml})$ was added to a reaction tube with a magnetic bar. The mixture was stirred at the indicated temperature for the specified reaction time. Upon completion of the reaction (monitored by TLC), the reaction mixture was quenched with saturated $\mathrm{Na}_{2} \mathrm{SO}_{3}$ aqueous solution $(2 \mathrm{ml})$. The aqueous phase was diluted with water $(3 \mathrm{ml})$ and extracted with EtOAc $(5 \mathrm{ml} \times 3)$. The combined organic extracts were dried over anhydrous $\mathrm{Na}_{2} \mathrm{SO}_{4}$, filtered, and concentrated under reduced pressure. The residue was purified over silica gel chromatography to afford 30-47.

General procedure for TEMPO-catalyzed halogenation of (hetero)arenes Substrate S48-S69 $(0.50 \mathrm{mmol})$, NCS $(80.2 \mathrm{mg}, 0.60 \mathrm{mmol})$, [TEMPO][OTf] $(30.5$ $\mathrm{mg}, 0.10 \mathrm{mmol})$, and $\mathrm{CHCl}_{3}(2.0 \mathrm{ml})$ was added to a reaction tube with a magnetic bar. The mixture was stirred at $25^{\circ} \mathrm{C}$ for $12 \mathrm{~h}$. Then, the reaction mixture was quenched with saturated $\mathrm{Na}_{2} \mathrm{SO}_{3}$ aqueous solution $(2 \mathrm{ml})$. The aqueous phase was diluted with water $(3 \mathrm{ml})$ and extracted with EtOAc $(5 \mathrm{ml} \times 3)$. The combined organic extracts were dried over anhydrous $\mathrm{Na}_{2} \mathrm{SO}_{4}$, filtered, and concentrated under reduced pressure. The residue was purified over silica gel chromatography to afford 48-69.

\section{Data availability}

All data that support the findings of this study are available in the online version of this paper in the accompanying Supplementary Information (including experimental procedures, compound characterization data).

Received: 18 January 2021; Accepted: 1 June 2021; Published online: 23 June 2021

\section{References}

1. Yoffe, D. et al. Bromine compounds. In Ullmann's Encyclopedia of Industrial Chemistry 7th edn, (ed Ley, C.) (John Wiley-VCH, 2013).

2. Larock, R. C. \& Zhang L. Aromatic halogenation. In Comprehensive Organic Transformations: A Guide to Functional Group Preparations 3rd edn, (ed Larock, R. C.) (John Wiley \& Sons, Inc., 2018).

3. de Meijere, A., Bräse, S. \& Oestreich M. (eds) Metal Catalyzed Cross-Coupling Reactions and More, 1st edn (Wiley-VCH, 2013).

4. Tang, M. L. \& Bao, Z. Halogenated materials as organic semiconductors. Chem. Mater. 23, 446-455 (2011).

5. Gribble, G. W. Natural organohalogens: a new frontier for medicinal agents? J. Chem. Edu. 81, 1441 (2004).

6. Smith, B. R., Eastman, C. M. \& Njardarson, J. T. Beyond C, H, O, and N! Analysis of the elemental composition of U.S. FDA approved drug architectures. J. Med. Chem. 57, 9764-9773 (2014).

7. Saikia, I., Borah, A. J. \& Phukan, P. Use of bromine and bromo-organic compounds in organic synthesis. Chem. Rev. 116, 6837-7042 (2016) 
8. Lu, Z. et al. CFBSA: a novel and practical chlorinating reagent. Chem Commun. 51, 14852-14855 (2015).

9. Wang, M. et al. Story of an age-old reagent: an electrophilic chlorination of arenes and heterocycles by 1-Chloro-1,2-benziodoxol-3-one. Org. Lett. 18, 1976-1979 (2016).

10. Fosu, S. C., Hambira, C. M., Chen, A. D., Fuchs, J. R. \& Nagib, D. A. Siteselective $\mathrm{C}-\mathrm{H}$ functionalization of (hetero)arenes via transient non-symmetric iodanes. Chem 5, 417-428 (2019).

11. Barluenga, J., González, J. M., Campos, P. J. \& Asensio, G. Iodine-induced stereoselective carbocyclizations: a new method for the synthesis of cyclohexane and cyclohexene derivatives. Angew. Chem. Int. Ed. Engl. 27, 1546-1547 (1988).

12. Barluenga, J., Trincado, M., Rubio, E. \& Gonzalez, J. M. Intramolecular arylation reactions of alkenes: a flexible approach to chromans and tetrahydroquinoline derivatives. J. Am. Chem. Soc. 126, 3416-3417 (2004).

13. Barluenga, J., González-Bobes, F., Ananthoju, S. R., García-Martín, M. A. \& González, J. M. Oxidative opening of cycloalkanols: an efficient entry to $\omega$ iodocarbonyl compounds. Angew. Chem. Int. Ed. 40, 3389-3392 (2001).

14. Barluenga, J., Trincado, M., Rubio, E. \& González, J. M. $\mathrm{IPy}_{2} \mathrm{BF}_{4}$-promoted intramolecular addition of masked and unmasked anilines to alkynes: direct assembly of 3-iodoindole cores. Angew. Chem. Int. Ed. 42, 2406-2409 (2003).

15. Snyder, S. A., Tang, Z.-Y. \& Gupta, R. Enantioselective total synthesis of $(-)$-napyradiomycin Al via asymmetric chlorination of an isolated olefin. J. Am. Chem. Soc. 131, 5744-5745 (2009).

16. Snyder, S. A. \& Treitler, D. S. $\mathrm{Et}_{2} \mathrm{SBrSbCl}_{5} \mathrm{Br}$ : an effective reagent for direct bromonium-induced polyene cyclizations. Angew. Chem. Int. Ed. 48, 7899-7903 (2009).

17. Snyder, S. A., Treitler, D. S. \& Brucks, A. P. Simple reagents for direct halonium-induced polyene cyclizations. J. Am. Chem. Soc. 132, 14303-14314 (2010).

18. Snyder, S. A., Gollner, A. \& Chiriac, M. I. Regioselective reactions for programmable resveratrol oligomer synthesis. Nature 474, 461-466 (2011)

19. Rodriguez, R. A. et al. Palau' chlor: a practical and reactive chlorinating reagent. J. Am. Chem. Soc. 136, 6908-6911 (2014).

20. Petrone, D. A., Ye, J. \& Lautens, M. Modern transition-metal-catalyzed carbon-halogen bond formation. Chem. Rev. 116, 8003-8104 (2016).

21. Djerassi, C. Brominations with N-Bromosuccinimide and related compounds. The Wohl-Ziegler reaction. Chem. Rev. 43, 271-317 (1948).

22. Denmark, S. E., Kuester, W. E. \& Burk, M. T. Catalytic, asymmetric halofunctionalization of alkenes-a critical perspective. Angew. Chem. Int. Ed. 51, 10938-10953 (2012).

23. Prakash, G. K. S. et al. N-Halosuccinimide $/ \mathrm{BF}_{3}-\mathrm{H}_{2} \mathrm{O}$, efficient electrophilic halogenating systems for aromatics. J. Am. Chem. Soc. 126, 15770-15776 (2004).

24. Mori, K. et al. Enantioselective synthesis of multisubstituted biaryl skeleton by chiral phosphoric acid catalyzed desymmetrization/kinetic resolution sequence. J. Am. Chem. Soc. 135, 3964-3970 (2013).

25. Vaidya, S. D., Toenjes, S. T., Yamamoto, N., Maddox, S. M. \& Gustafson, J. L. Catalytic atroposelective synthesis of N-Aryl quinoid compounds. J. Am. Chem. Soc. 142, 2198-2203 (2020).

26. Dobish, M. C. \& Johnston, J. N. Achiral counterion control of enantioselectivity in a Brønsted acid-catalyzed iodolactonization. J. Am. Chem. Soc. 134, 6068-6071 (2012).

27. He, X., Wang, X., Tse, Y. S., Ke, Z. \& Yeung, Y. Y. Applications of selenonium cations as lewis acids in organocatalytic reactions. Angew. Chem. Int. Ed. 57, 12869-12873 (2018).

28. Yamamoto, H., Zhang, Y. \& Shibatomi, K. Lewis acid catalyzed highly selective halogenation of aromatic compounds. Synlett 37, 2837-2842 (2005).

29. Racys, D. T., Warrilow, C. E., Pimlott, S. L. \& Sutherland, A. Highly regioselective iodination of arenes via iron(III)-catalyzed activation of $\mathrm{N}$ iodosuccinimide. Org. Lett. 17, 4782-4785 (2015).

30. Mo, F. et al. Gold-catalyzed halogenation of aromatics by N-halosuccinimides. Angew. Chem. Int. Ed. 49, 2028-2032 (2010).

31. Zhou, P. et al. Iron-catalyzed asymmetric haloazidation of $\alpha, \beta$-unsaturated ketones: construction of organic azides with two vicinal stereocenters. J. Am. Chem. Soc. 139, 13414-13419 (2017).

32. Zhou, P. et al. Catalytic asymmetric intra- and intermolecular haloetherification of enones: an efficient approach to (-)-centrolobine. ACS Catal. 6, 7778-7783 (2016).

33. Mostafa, M. A. B., Bowley, R. M., Racys, D. T., Henry, M. C. \& Sutherland, A. Iron(III)-catalyzed chlorination of activated arenes. J. Org. Chem. 82, 7529-7537 (2017).

34. Combe, S. H., Hosseini, A., Song, L., Hausmann, H. \& Schreiner, P. R. Catalytic halogen bond activation in the benzylic $\mathrm{C}-\mathrm{H}$ bond iodination with iodohydantoins. Org. Lett. 19, 6156-6159 (2017).

35. Chan, Y. C. \& Yeung, Y. Y. Halogen bond catalyzed bromocarbocyclization. Angew. Chem. Int. Ed. 57, 3483-3487 (2018).
36. Denmark, S. E. \& Beutner, G. L. Lewis base catalysis in organic synthesis. Angew. Chem. Int. Ed. 47, 1560-1638 (2008).

37. Sakakura, A. \& Ishihara, K. Stereoselective electrophilic cyclization. Chem. Rec. 15, 728-742 (2015)

38. Chung, W. J. \& Vanderwal, C. D. Stereoselective halogenation in natural product synthesis. Angew. Chem. Int. Ed. 55, 4396-4434 (2016).

39. Cheng, Y. A., Yu, W. Z. \& Yeung, Y.-Y. Recent advances in asymmetric intraand intermolecular halofunctionalizations of alkenes. Org. Biomol. Chem. 12, 2333-2343 (2014)

40. Xiong, X. \& Yeung, Y. Y. Highly ortho-selective chlorination of anilines using a secondary ammonium salt organocatalyst. Angew. Chem. Int. Ed. 55, 16101-16105 (2016).

41. Xiong, X. D. \& Yeung, Y. Y. Ammonium salt-catalyzed highly practical orthoselective monohalogenation and phenylselenation of phenols: scope and applications. ACS Catal. 8, 4033-4043 (2018).

42. Haas, J., Bissmire, S. \& Wirth, T. Iodine monochloride-amine complexes: an experimental and computational approach to new chiral electrophiles. Chem. Eur. J. 11, 5777-5785 (2005).

43. Zhang, W., Xu, H., Xu, H. \& Tang, W. DABCO-catalyzed 1,4bromolactonization of conjugated enynes: highly stereoselective formation of a stereogenic center and an axially chiral allene. J. Am. Chem. Soc. 131, 3832-3833 (2009).

44. Whitehead, D. C., Yousefi, R., Jaganathan, A. \& Borhan, B. An organocatalytic asymmetric chlorolactonization. J. Am. Chem. Soc. 132, 3298-3300 (2010).

45. Jaganathan, A., Staples, R. J. \& Borhan, B. Kinetic resolution of unsaturated amides in a chlorocyclization reaction: concomitant enantiomer differentiation and face selective alkene chlorination by a single catalyst. J. Am. Chem. Soc. 135, 14806-14813 (2013).

46. Yousefi, R., Ashtekar, K. D., Whitehead, D. C., Jackson, J. E. \& Borhan, B. Dissecting the stereocontrol elements of a catalytic asymmetric chlorolactonization: syn addition obviates bridging chloronium. J. Am. Chem. Soc. 135, 14524-14527 (2013).

47. Soltanzadeh, B., Jaganathan, A., Staples, R. J. \& Borhan, B. Highly Stereoselective Intermolecular Haloetherification and haloesterification of allyl amides. Angew. Chem. Int. Ed. 54, 9517-9522 (2015).

48. Soltanzadeh, B. et al. Highly regio- and enantioselective vicinal dihalogenation of allyl amides. J. Am. Chem. Soc. 139, 2132-2135 (2017).

49. Nicolaou, K. C., Simmons, N. L., Ying, Y., Heretsch, P. M. \& Chen, J. S. Enantioselective dichlorination of allylic alcohols. J. Am. Chem. Soc. 133 8134-8137 (2011).

50. Samanta, R. C. \& Yamamoto, H. Selective halogenation using an aniline catalyst. Chem. Eur. J. 21, 11976-11979 (2015).

51. Arnold, A. M., Pothig, A., Drees, M. \& Gulder, T. NXS, morpholine, and HFIP: the ideal combination for biomimetic haliranium-induced polyene cyclizations. J. Am. Chem. Soc. 140, 4344-4353 (2018).

52. Liu, Y., Tse, Y.-L. S., Kwong, F. Y. \& Yeung, Y.-Y. Accessing axially chiral biaryls via organocatalytic enantioselective dynamic-kinetic resolutionsemipinacol rearrangement. ACS Catal. 7, 4435-4440 (2017).

53. Horibe, T., Tsuji, Y. \& Ishihara, $\mathrm{K}$. Thiourea- $\mathrm{I}_{2}$ as Lewis base-Lewis acid cooperative catalysts for iodochlorination of alkene with in situ-generated I-Cl. ACS Catal. 8, 6362-6366 (2018).

54. Iida, K., Ishida, S., Watanabe, T. \& Arai, T. Disulfide-catalyzed iodination of electron-rich aromatic compounds. J. Org. Chem. 84, 7411-7417 (2019).

55. Hirose, Y., Yamazaki, M., Nogata, M., Nakamura, A. \& Maegawa, T. Aromatic halogenation using $\mathrm{N}$-halosuccinimide and $\mathrm{PhSSiMe}_{3}$ or PhSSPh. J. Org. Chem. 84, 7405-7410 (2019).

56. Cao, Q., Luo, J. \& Zhao, X. Chiral sulfide catalysis for desymmetrizing enantioselective chlorination. Angew. Chem. Int. Ed. 58, 1315-1319 (2019).

57. Samanta, R. C. \& Yamamoto, H. Catalytic asymmetric bromocyclization of polyenes. J. Am. Chem. Soc. 139, 1460-1463 (2017).

58. Ke, Z., Tan, C. K., Chen, F. \& Yeung, Y.-Y. Catalytic asymmetric bromoetherification and desymmetrization of olefinic 1,3-diols with C2symmetric sulfides. J. Am. Chem. Soc. 136, 5627-5630 (2014).

59. Zhou, L., Tan, C. K., Jiang, X., Chen, F. \& Yeung, Y.-Y. Asymmetric bromolactonization using amino-thiocarbamate catalyst. J. Am. Chem. Soc. 132, 15474-15476 (2010)

60. Jiang, X., Tan, C. K., Zhou, L. \& Yeung, Y.-Y. Enantioselective bromolactonization using an S-Alkyl thiocarbamate catalyst. Angew. Chem. Int. Ed. 51, 7771-7775 (2012).

61. Zhao, Y., Jiang, X. \& Yeung, Y.-Y. Catalytic, enantioselective, and highly chemoselective bromocyclization of olefinic dicarbonyl compounds. Angew. Chem. Int. Ed. 52, 8597-8601 (2013).

62. Nishii, Y., Ikeda, M., Hayashi, Y., Kawauchi, S. \& Miura, M. Triptycenyl sulfide: a practical and active catalyst for electrophilic aromatic halogenation using N-Halosuccinimides. J. Am. Chem. Soc. 142, 1621-1629 (2020).

63. Maddox, S. M., Nalbandian, C. J., Smith, D. E. \& Gustafson, J. L. A practical Lewis base catalyzed electrophilic chlorination of arenes and heterocycles. Org. Lett. 17, 1042-1045 (2015). 
64. Denmark, S. E., Burk, M. T. \& Hoover, A. J. On the absolute configurational stability of bromonium and chloronium ions. J. Am. Chem. Soc. 132 1232-1233 (2010).

65. Denmark, S. E. \& Burk, M. T. Enantioselective bromocycloetherification by Lewis base/chiral Brønsted acid cooperative catalysis. Org. Lett. 14, 256-259 (2012).

66. Denmark, S. E. \& Burk, M. T. Development and mechanism of an enantioselective bromocycloetherification reaction via Lewis base/chiral Brønsted acid cooperative catalysis. Chirality 26, 344-355 (2014).

67. Cresswell, A. J., Eey, S. T. C. \& Denmark, S. E. Catalytic, stereospecific syndichlorination of alkenes. Nat. Chem. 7, 146-152 (2015).

68. Denmark, S. E., Ryabchuk, P., Burk, M. T. \& Gilbert, B. B. Toward catalytic, enantioselective chlorolactonization of 1,2-disubstituted styrenyl carboxylic acids. J. Org. Chem. 81, 10411-10423 (2016).

69. Tao, Z., Robb, K. A., Zhao, K. \& Denmark, S. E. Enantioselective Lewis basecatalyzed sulfenocyclization of polyenes. J. Am. Chem. Soc. 140, 3569-3573 (2018).

70. Chen, F., Tan, C. K. \& Yeung, Y.-Y. C2-symmetric cyclic selenium-catalyzed enantioselective bromoaminocyclization. J. Am. Chem. Soc. 135, 1232-1235 (2013).

71. Sawamura, Y., Nakatsuji, H., Sakakura, A. \& Ishihara, K. "Phosphite-urea" cooperative high-turnover catalysts for the highly selective bromocyclization of homogeranylarenes. Chem. Sci. 4, 4181-4186 (2013).

72. Sakakura, A., Ukai, A. \& Ishihara, K. Enantioselective halocyclization of polyprenoids induced by nucleophilic phosphoramidites. Nature 445, 900-903 (2007).

73. Huy, P. H., Hauch, T. \& Filbrich, I. Lewis base catalyzed nucleophilic substitutions of alcohols. Synlett 27, 2631-2636 (2016).

74. Huy, P. H., Motsch, S. \& Kappler, S. M. Formamides as Lewis base catalysts in $\mathrm{SN}$ reactions-efficient transformation of alcohols into chlorides, amines, and ethers. Angew. Chem. Int. Ed. 55, 10145-10149 (2016).

75. Denmark, S. E. \& Burk, M. T. Lewis base catalysis of bromo- and iodolactonization, and cycloetherification. Proc. Natl. Acad. Sci. USA 107, 20655-20660 (2010).

76. Song, S. et al. DMSO-catalysed late-stage chlorination of (hetero)arenes. Nat. Catal. 3, 107-115 (2020).

77. Cinquini, M. \& Colonna, S. Synthesis of a-halogeno-sulphoxides. J. Chem. Soc., Perkin Trans. 1, 1883-1886 (1972).

78. Tomita, R., Yasu, Y., Koike, T. \& Akita, M. Combining photoredox-catalyzed trifluoromethylation and oxidation with DMSO: facile synthesis of $\alpha$ trifluoromethylated ketones from aromatic alkenes. Angew. Chem. Int. Ed. 53, 7144-7148 (2014).

79. Ashikari, Y., Nokami, T. \& Yoshida, J.-I. Integrated electrochemical-chemical oxidation mediated by alkoxysulfonium ions. J. Am. Chem. Soc. 133, 11840-11843 (2011).

80. $\mathrm{Ai}, \mathrm{L}$. et al. Oxidative $\beta$-halogenation of alcohols: a concise and diastereoselective approach to halohydrins. Synlett 30, 437-441 (2019).

81. Song, S. et al. From simple organobromides or olefins to highly value-added bromohydrins: a versatile performance of dimethyl sulfoxide. Green. Chem. 17, 2727-2731 (2015).

82. Giera, J., Sobczyk, L., Lux, F. \& Paetzold, R. Correlation between the dipole moments and thermodynamical data of iodine complexes with organic oxides, sulfides, and selenides. J. Phys. Chem. 84, 2602-2605 (1980).

83. Ryland, B. L. \& Stahl, S. S. Practical aerobic oxidations of alcohols and amines with homogeneous copper/TEMPO and related catalyst systems. Angew. Chem. Int. Ed. 53, 8824-8838 (2014).

84. Nutting, J. E., Rafiee, M. \& Stahl, S. S. Tetramethylpiperidine N-Oxyl (TEMPO), phthalimide N-Oxyl (PINO), and related N-Oxyl species: electrochemical properties and their use in electrocatalytic reactions. Chem. Rev. 118, 4834-4885 (2018).

85. Tebben, L. \& Studer, A. Nitroxides: applications in synthesis and in polymer chemistry. Angew. Chem. Int. Ed. 50, 5034-5068 (2011).

86. During the preparation of our manuscript, Morita et al. reported nitroxyl catalysts for intermolecular bromolactonization, see: Moriyama, K., Kuramochi, M., Tsuzuki, S., Fujii, K. \& Morita, T. Nitroxyl catalysts for sixmembered ring bromolactonization and intermolecular bromoesterification of alkenes with carboxylic acids. Org. Lett. 23, 268-273 (2021).

87. Sridharan, V., Suryavanshi, P. A. \& Menéndez, J. C. Advances in the chemistry of tetrahydroquinolines. Chem. Rev. 111, 7157-7259 (2011).

88. Trenor, S. R., Shultz, A. R., Love, B. J. \& Long, T. E. Coumarins in polymers: from light harvesting to photo-cross-linkable tissue scaffolds. Chem. Rev. 104, 3059-3078 (2004).

89. Wang, W. et al. Nitromethane-enabled fluorination of styrenes and arenes. CCS Chem. 2, 566-575 (2020).

90. Hickey, D. P. et al. Predicting electrocatalytic properties: modeling structure-activity relationships of nitroxyl radicals. J. Am. Chem. Soc. 137, 16179-16186 (2015)
91. Ryu, I., Matsubara, H., Yasuda, S., Nakamura, H. \& Curran, D. P. Phasevanishing reactions that use fluorous media as a phase screen. Facile, controlled bromination of alkenes by dibromine and dealkylation of aromatic ethers by boron tribromide. J. Am. Chem. Soc. 124, 12946-12947 (2002).

92. Kavala, V., Naik, S. \& Patel, B. K. A new recyclable ditribromide reagent for efficient bromination under solvent free condition. J. Org. Chem. 70, 4267-4271 (2005)

93. Hernandez-Torres, G., Tan, B. \& Barbas, C. F. 3rd Organocatalysis as a safe practical method for the stereospecific dibromination of unsaturated compounds. Org. Lett. 14, 1858-1861 (2012).

94. Liu, R., Liang, X., Dong, C. \& Hu, X. Transition-metal-free: a highly efficient catalytic aerobic alcohol oxidation process. J. Am. Chem. Soc. 126, 4112-4113 (2004).

95. Liu, R., Dong, C., Liang, X., Wang, X. \& Hu, X. Highly efficient catalytic aerobic oxidations of benzylic alcohols in water. J. Org. Chem. 70, 729-731 (2005).

96. Gaffen, J. R. et al. A simple and effective method of determining Lewis acidity by using fluorescence. Chem 5, 1567-1583 (2019).

97. Beckett, M. A., Strickland, G. C., Holland, J. R. \& Sukumar Varma, K. A convenient n.m.r. method for the measurement of Lewis acidity at boron centres: correlation of reaction rates of Lewis acid initiated epoxide polymerizations with Lewis acidity. Polymer 37, 4629-4631 (1996).

98. Mayer, U., Gutmann, V. \& Gerger, W. The acceptor number-a quantitative empirical parameter for the electrophilic properties of solvents. Monatsh. Chem. 106, 1235-1257 (1975).

99. Frisch, M. J. et al. Gaussian 09, Revision A.01 (Gaussian, Inc., 2009).

\section{Acknowledgements}

Financial support from the National Key Research and Development Project (No. 2019YFC1708902), the Beijing Nova Program (No. Z201100006820099), the National Natural Science Foundation of China (Nos. 21871011, 81821004), the Drug Innovation Major Project (2018ZX09711-001), and the Major Changes in the Central Level Support Projects (2060302). We thank Rongheng Dai in this group for reproducing the results of $1,14,64$, and 68

\section{Author contributions}

W.W., N.J., and S.S. conceived and designed the experiments; W.W. carried out most of experiments; X.Y., L.A., Z.G., N.J., and S.S. analyzed data; X.L. conducted the DFT calculation; W.W., X.L., N.J., and S.S. wrote the paper; S.S. and N.J. directed the project.

\section{Competing interests}

The authors declare no competing interests.

\section{Additional information}

Supplementary information The online version contains supplementary material available at https://doi.org/10.1038/s41467-021-24174-w.

Correspondence and requests for materials should be addressed to S.S.

Peer review information Nature Communications thanks Scott Denmark and the other anonymous reviewer(s) for their contribution to the peer review of this work.

Reprints and permission information is available at http://www.nature.com/reprints

Publisher's note Springer Nature remains neutral with regard to jurisdictional claims in published maps and institutional affiliations.

Open Access This article is licensed under a Creative Commons Attribution 4.0 International License, which permits use, sharing, adaptation, distribution and reproduction in any medium or format, as long as you give appropriate credit to the original author(s) and the source, provide a link to the Creative Commons license, and indicate if changes were made. The images or other third party material in this article are included in the article's Creative Commons license, unless indicated otherwise in a credit line to the material. If material is not included in the article's Creative Commons license and your intended use is not permitted by statutory regulation or exceeds the permitted use, you will need to obtain permission directly from the copyright holder. To view a copy of this license, visit http://creativecommons.org/ licenses/by/4.0/.

(C) The Author(s) 2021 